\section{Influence of subconjunctival steroid injection on blood glucose profile in diabetic rats}

\begin{abstract}
Purpose The influence of subconjunctival steroid injection on blood glucose concentration was investigated in rats with streptozotocin (STZ)-induced diabetes. Methods Adult male Wistar rats with STZinduced diabetes $(n=10)$ and normal controls $(n=10)$ received subconjunctival injections of $0.1 \mathrm{ml}$ of $0.4 \%$ dexamethasone or saline. Blood glucose concentrations were measured before and 3, 6, 12, 18 and $24 \mathrm{~h}$ after treatment. Results In the STZ group, subconjunctival injection of steroids $(p=0.0013)$ or saline ( $p=0.0037)$ significantly increased the blood glucose level $3 \mathrm{~h}$ after treatment. In the control group, the blood glucose concentration was not elevated by subconjunctival injection. In both STZ and control groups, the blood glucose concentration was significantly higher after steroid injection than after saline injection throughout the $24 \mathrm{~h}$ study period. Conclusions Subconjunctival steroid injection induced a significant blood glucose increase in both diabetic and control rats. For diabetic rats, the subconjunctival injection itself constituted stress that resulted in glucose elevation.
\end{abstract}

Key words Blood glucose concentration, Diabetes mellitus, Rat, Steroid, Streptozotocin (STZ), Subconjunctival injection

H. Fukushima

S. Kato

Y. Hayashi

T. Oshika

Department of

Ophthalmology

University of Tokyo School

of Medicine

Tokyo, Japan

Harumi Fukushima, MD Division of Ophthalmology Tokyo University Branch

Hospital

3-28-6 Mejirodai

Bunkyo-ku

Tokyo, 112-8688, Japan

Tel/fax: +8133943 3749

e-mail:

fharumi@muc.biglobe.ne.jp

clearly the most common indication for steroid use. In cataract surgery, subconjunctival steroid injection has been widely used in the belief that it will reduce post-operative inflammation. ${ }^{1-5}$ Subconjunctival steroids can be absorbed into the systemic circulation, ${ }^{6}$ which may raise blood glucose levels in diabetic patients. Little is known, however, about the glycaemic profile following subconjunctival steroid injection. The aim of this study was to assess the effect of subconjunctival steroid injection on blood glucose concentrations in rats with streptozotocin (STZ)-induced diabetes.
HARUMI FUKUSHIMA, SATOSHI KATO, YOSHIE HAYASHI, TETSURO OSHIKA

\section{Materials and methods \\ Experimental animals}

Twenty male 6-week-old Wistar rats (weighing 140-160 g) were used in this study. All rats were housed in a quiet room with constant temperature $\left(23-25^{\circ} \mathrm{C}\right)$, humidity $(55-65 \%)$ and light (illumination from 0600 to 1800 hours). They were allowed free access to regular food (Nippon Bio Supp Center, Tokyo, Japan) and tap water. The current experiments were performed in accordance with institutional guidelines for animal experiments at the University of Tokyo.

\section{Induction of diabetes}

Rats were randomly divided into a diabetic group (STZ group) and a non-diabetic group (control group). After a $12 \mathrm{~h}$ fast, the rats in the STZ group $(n=10)$ were anaesthetised with intramuscular ketamine hydrochloride and xylazine hydrochloride. The STZ (Wako Pure Chemical Industries, Osaka, Japan) was freshly dissolved in $0.1 \mathrm{ml}$ of $50 \mathrm{mM}$ citrate buffer, $\mathrm{pH}$ 4.5 , and the $45 \mathrm{mg} / \mathrm{kg}$ solution injected into the tail vein. The rats in the control group $(n=10)$ received the same anaesthesia and venous injection of an equivalent volume of citrate buffer. Blood glucose levels were checked 7 days after STZ administration using a glucose meter (Sanwa Kagaku Kenkyusho, Nagoya, Japan). The STZ-treated rats displayed mild hyperglycaemia $(165.9 \pm 34.3 \mathrm{mg} / \mathrm{dl})$ compared with the control group $(124.9 \pm 33.3 \mathrm{mg} / \mathrm{dl})$.

\section{Subconjunctival injection}

Seven days after STZ administration, rats were fasted for $12 \mathrm{~h}$ and anaesthetised with ketamines hydrochloride and xylazine hydrochloride. In both the STZ group and the control group, half the rats received a subconjunctival injection of $0.1 \mathrm{ml}$ of $0.4 \%$ dexamethasone sodium phosphate, and the other half a subconjunctival injection of $0.1 \mathrm{ml}$ saline. The injections were into the right eye. One week later, the steroid 


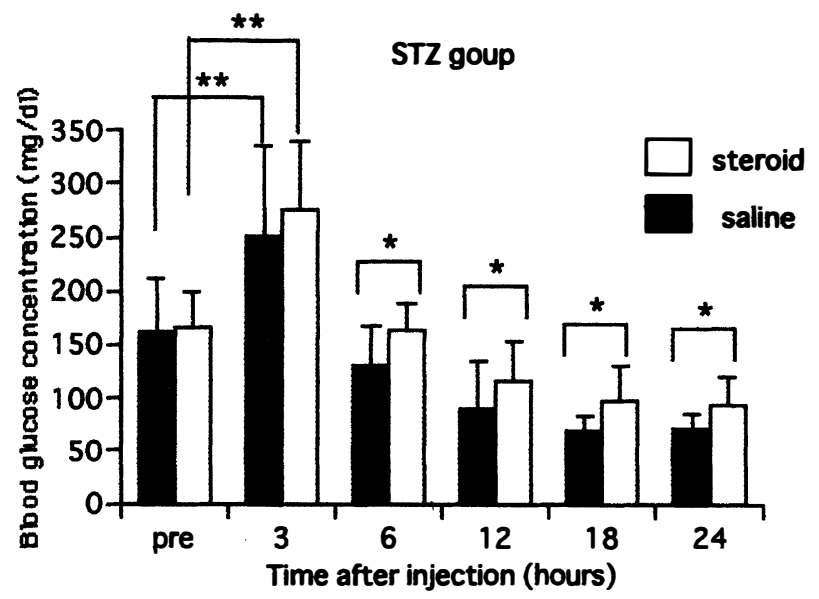

Fig. 1. Blood glucose concentration after subconjunctival steroid or saline injection in the STZ group. ${ }^{*} \mathrm{p}<0.05$ (unpaired $\mathrm{t}$-test);

${ }^{* *}$ repeated measures ANOVA and post-hoc test.

and saline groups were exchanged and the same procedures were performed on the left eye of each animal.

\section{Measurement of blood glucose concentration}

The blood glucose concentration was measured before and $3,6,12,18$ and $24 \mathrm{~h}$ after subconjunctival injection. All rats were fasted during the study.

\section{Statistical analysis}

Statistical significance was tested using an unpaired $t$ test (two-tailed), repeated measures ANOVA and a posthoc test.

\section{Results}

In the STZ group, subconjunctival injections of steroids $(p=0.0013)$ ard saline $(p=0.0037)$ induced significant increases in blood glucose $3 \mathrm{~h}$ after treatment (Fig. 1). In the control group, the blood glucose concentration did not rise irı response to the subconjunctival injection of either dexamethasone or saline (Fig. 2).

In the STZ group, the blood glucose concentration between 3 and $24 \mathrm{~h}$ after treatment was significantly higher after steroid injection than after saline injection (Fig. 1). Among controls, the difference between the steroid and saline injection groups was statistically significant between 3 and $24 \mathrm{~h}$ after treatment (Fig. 2).

\section{Discussion}

Weijtens et al. ${ }^{7}$ investigated the concentration of dexamethasone in the aqueous, vitreous and serum after subconjunctival injection. They reported a mean maximum serum concentration of $32.4 \mathrm{ng} / \mathrm{ml}$ approximately $30 \mathrm{~min}$ after subconjunctival injection of $2.5 \mathrm{mg}$ dexamethasone disodium phosphate, which was higher than the level obtained with oral administration of dexamethasone. The serum dexamethasone

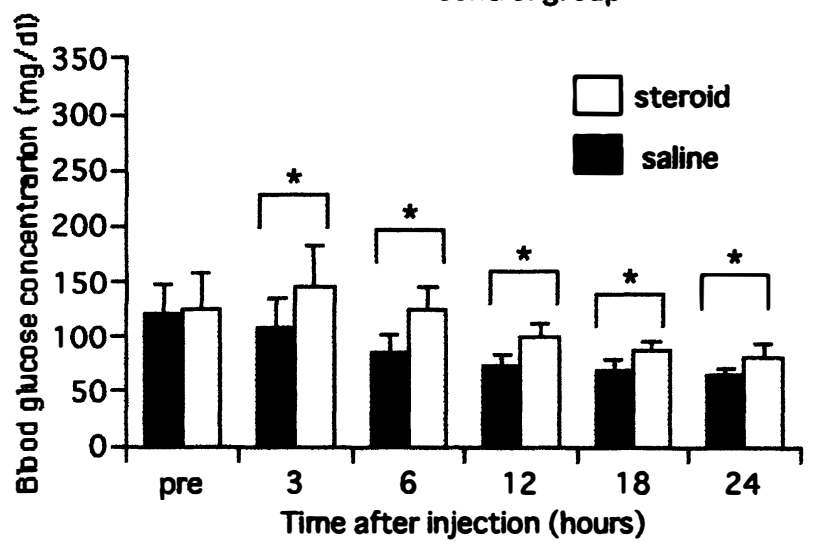

Fig. 2. Blood glucose concentration after subconjunctival steroid or saline injection in the control group. ${ }^{*} \mathrm{p}<0.05$ (unpaired $\mathrm{t}$-test).

concentration curve was best described by log-linear regression. The titre of $0.3 \mathrm{ml}$ of $0.4 \%$ dexamethasone sodium phosphate (=1.2 $\mathrm{mg}$ of dexamethasone) is equivalent to $7.5-9 \mathrm{mg}$ of prednisolone. Steroids absorbed into the systemic circulation may increase the blood glucose level by stimulating hepatic glucose metabolism $^{8}$ and peripheral glucose production. ${ }^{9}$ However, the blood glucose concentration profile after subconjunctival steroid injection has not been reported. We assessed the effect of subconjunctival steroid injection on the blood glucose level using rats with STZinduced moderate diabetes.

Subconjunctival injection of saline significantly elevated blood glucose in the STZ group, but not in the control group. These results indicate that subconjunctival injection itself places considerable stress on rats, leading to hyperglycaemia in the diabetic rats. Activation of the sympathetic nervous system and the consequent release of catecholamines can contribute to the development of hyperglycaemia. Catecholamines directly stimulate glucose production by the liver ${ }^{10,11}$ and also interfere with insulin-mediated glucose uptake. ${ }^{10,12}$ Unless pancreatic islet function is simultaneously diminished, hyperglycaemia strongly stimulates insulin secretion and inhibits the release of glucagon. These effects of hyperglycaemia on pancreatic islet function usually work to maintain the glucose level during stressful situations in normal subjects. However, diabetic patients who suffer from impaired islet responses to glucose will be particularly prone to the development of marked hyperglycaemia under stressful conditions. ${ }^{13}$ In the present study, the stress of subconjunctival injection induced hyperglycaemia in diabetic rats. On the other hand, the control rats were able to handle the stress of subconjunctival injection without significant fluctuations in glucose level.

The blood glucose concentration was significantly higher after subconjunctival steroid injection than after saline injection in both the control group and the STZ group. The difference between the steroid and saline groups remained statistically significant throughout the $24 \mathrm{~h}$ study period. Blood glucose concentration peaked $3 \mathrm{~h}$ after subconjunctival injection, followed by a gradual 
decline due to fasting during the study. These data indicate that subconjunctival steroid injection exerts a hyperglycaemic effect which lasts for at least $24 \mathrm{~h}$. However, the relative volume of chemicals injected in this study was $100 \mu \mathrm{l}(670 \mu \mathrm{l} / \mathrm{kg})$, which is more than 100 times the volume usually used in humans $(6 \mu \mathrm{l} / \mathrm{kg})$. Thus, the current results cannot simply be extrapolated to diabetic patients. Nevertheless, we recently found that subconjunctival steroid injection at the completion of cataract surgery induced a transient but significant blood glucose increase in diabetic patients on the day of surgery (unpublished data). Although subconjunctival steroid injection at the completion of cataract surgery is believed to reduce post-operative inflammation, ${ }^{1-5}$ recent studies have demonstrated no such suppression in uncomplicated cases ${ }^{14,15}$ or in diabetic eyes with neither proliferative retinopathy nor intraoperative complications. ${ }^{16}$ We advocate that the usefulness and necessity of subconjunctival steroid injection be carefully reconsidered in light of the possible adverse effects, as shown herein, especially in diabetic patients.

\section{References}

1. Avasthi P, Bhatia R. Role of subconjunctival injection of steroid in extracapsular extraction of lens. Int Surg 1969;51:537-9.

2. Buxton J, Smith D, Brownstein S. Cataract extraction and subconjunctival repository corticosteroids. Ann Ophthalmol 1971;3:1871-6.

3. Corbett M, Hingorani M, Boulton J, et al. Subconjunctival betamethasone is of benefit after cataract surgery. Eye 1993;7:744-8

4. Leaming D. Practice styles and preferences of ASCRS members: 1998 survey. J Cataract Refract Surg 1999;25:851-9.
5. Oshika T, Masuda K, Majima Y, et al. Current trends in cataract and refractive surgery in Japan: 1995 survey. Jpn J Ophthalmol 1996;40:419-33.

6. Tsuji A, Tamai I, Sasaki K. Hydrolysis of prednisolone succinate by esterase in rabbit ocular tissue. Ophthalmic Res 1987;19:322-9.

7. Weijtens $\mathrm{O}$, Feron $\mathrm{E}$, Schoemaker R, et al. High concentration of dexamethasone in aqueous and vitreous after subconjunctival injection. Am J Ophthalmol 1999;128:192-7.

8. Delaunay F, Khan A, Cintra A, et al. Pancreatic beta cells are important targets for the diabetogenic effects of glucocorticoids. J Clin Invest 1997;100:2094-8.

9. Wajngot A, Khan A, Giacca A, et al. Dexamethasone increases glucose cycling, but not glucose production, in healthy subjects. Am J Physiol 1990;259:E626-32.

10. Deibert D, DeFronzo R. Epinephrine-induced insulin resistance in man. J Clin Invest 1980;65:717-21.

11. Rizza R, Cryer P, Haymond M, et al. Adrenergic mechanisms for the effects of epinephrine on glucose production and clearance in man. J Clin Invest 1980;65:682-9.

12. Chiasson J, Shikama H, Chu D, et al. Inhibitory effect of epinephrine on insulin-stimulated glucose uptake by skeletal muscle. J Clin Invest 1981;68:706-13.

13. Halter J, Beard J, Porte DJ. Islet function and stress hyperglycemia: plasma glucose and epinephrine interaction. Am J Physiol 1984;247:E47-52.

14. Shah S, McHugh J, Spalton D. The effects of subconjunctival betamethasone on the blood aqueous barrier following cataract surgery: a double-blind randomized prospective study. Br J Ophthalmol 1992;76:475-8.

15. Schmitt K, Hessemer V. Ist eine subkonjunktivale Steroidgabe zusatzlich zur Lokaltherapie nach Kataraktoperationen notwendig? Ophthalmologe 1995;92:303-6.

16. Fukushima $H$, Kato S, Kaiya T, et al. Effect of subconjunctival corticosteroid immediately after cataract surgery in diabetic patients [in Japanese]. Jpn J Clin Ophthalmol 1999;53:2001-4. 